\title{
Evaluation of Various Factors Affecting Bioconversion of L-Tyrosine to L-DOPA by Yeast Yarrowia lipolytica-NCIM 3450 Using Response Surface Methodology
}

\author{
Swati T. Gurme $\cdot$ Shripad N. Surwase $\cdot$ \\ Sushama A. Patil · Jyoti P. Jadhav
}

Received: 27 January 2014/ Accepted: 17 April 2014/Published online: 7 May 2014

(C) The Author(s) 2014. This article is published with open access at Springerlink.com

\begin{abstract}
Dihydroxy L-phenylalanine (L-DOPA) is considered a potent drug for the treatment of Parkinson disease. Physical and nutritional parameters where optimized by using Yarrowia lipolytica-NCIM 3450 to accomplished the highest production of L-DOPA. Screenings of critical components were completed by using a Plackett-Burman design, while further optimization was carried out using the Box-Behnken design. The optimized factor levels predicted by the model were $\mathrm{pH}$ 6.1, $1.659 \mathrm{~g} \mathrm{~L}^{-1}$ yeast extract, $1.491 \mathrm{~g} \mathrm{~L}^{-1} \mathrm{~L}$-tyrosine and $0.0290 \mathrm{~g} \mathrm{~L}^{-1} \mathrm{CuSO}_{4}$. The predicted yield of L-DOPA with these levels was $1.319 \mathrm{~g} \mathrm{~L}^{-1}$, while actual yield obtained was $1.273 \mathrm{~g} \mathrm{~L}^{-1}$. The statistical analysis revealed that model is significant with $F$ value 19.55 and $\mathrm{R}^{2}$ value 0.9514 . This process resulted in a 3.594 -fold increase in the yield of $\mathrm{L}^{-}$ DOPA. L-DOPA was confirmed by HPTLC and HPLC analysis. Thus, Yarrowia lipolytica-NCIM 3450 has potential to be a new source for the production of L-DOPA.
\end{abstract}

Keywords L-DOPA $\cdot$ L-tyrosine $\cdot$ RSM $\cdot$ Yarrowia lipolytica

\section{Introduction}

Parkinson's disease affects individuals worldwide, with the incidence increasing sharply with age to about 200-250 per 20 million in those over 60 years old. L-DOPA (3,4-dihydroxy phenyl L-alanine) is the drug of choice in the treatment of Parkinson's disease and for controlling the changes in enzymes of energy metabolism in Myocardium following neurogenic injury [1]. L-DOPA is produced from L-tyrosine by one-step oxidation reaction by which is

Electronic supplementary material The online version of this article (doi:10.1007/s13659-014-0017-3) contains supplementary material, which is available to authorized users.

S. T. Gurme · S. A. Patil · J. P. Jadhav $(\bowtie)$

Department of Biotechnology, Shivaji University, Vidyanagar,

Kolhapur 416004, India

e-mail: jpjbiochem@gmail.com

S. N. Surwase

Department of Microbiology, Shivaji University,

Kolhapur 416004, India catalyzed by enzyme tyrosinase [2, 3]. Tyrosinases (EC 1.14.1.18.1) are widely distributed in Nature and have been purified to homogeneity from both microbial and plant sources [4].

About 250 tons of L-DOPA is now supplied per year with trade names Dopar, Larodopar, Sinemet, [5, 6]. As the demand for L-DOPA is high, its production by various biological sources is highly relevant [7]. L-DOPA have been produced earlier by several biological sources that include Erwinia herbicola [8], Aspergillus oryzae [9], Yarrowia lipolytica NRRL-143 [10], Bacillus sp. JPJ [11] and Brevundimonas sp. SGJ [12], Acremonium rutilum [13] and Egyptian halophilic black yeast [14]. In addition, plant sources, such as cell suspension cultures of banana and Portulaca grandiflora, have also been reported for L-DOPA production [15, 16]. The seeds of $M$. pruriens [17], M. monosperma [18] have been used for L-DOPA production. Most of the L-DOPA sold commercially is chemically synthesized that involves eight reaction steps. Chemical synthesis of L-DOPA is a time-consuming process which involves several chemicals that are extremely 
costly and requires catalysts that are not ecofriendly $[13,19]$. In contrast to chemical production, biotechnological production of L-DOPA by microorganisms is environmental friendly and enables an enhanced product under simple process conditions [8].

The optimization of fermentation conditions, particularly physical and nutritional parameters are of primary importance in the development of any fermentation process owing to their impact on the economy and practicability of the process [20]. Classical method have some disadvantages like more time consumption, laborious process and high cost, in addition to this, it fails to determine the combined effect of different factors. Thus researchers are encouraged to apply statistical approaches such as 'response surface methodology' (RSM), which provide a great amount of information based on only a small number of experiments [21, 22]. In the present study PlackettBurman design and Box-Behnken design of the RSM were used to optimize the medium compositions and cultivation conditions for the highest L-DOPA production by using Y. lipolytica-NCIM 3450.

\section{Results and Discussion}

\subsection{Plackett-Burman Design for Screening of Critical Factors}

Statistical analysis using a Plackett-Burman design implies that $\mathrm{pH}\left(\mathrm{X}_{1}\right)$, yeast extract $\left(\mathrm{X}_{3}\right)$, L-tyrosine $\left(\mathrm{X}_{7}\right)$, and $\mathrm{CuSO}_{4}\left(\mathrm{X}_{8}\right)$ were significantly affected the L-DOPA production. The remaining components were found to be insignificant. The 'Pareto chart' (Fig. 1) showed that value of L-tyrosine $\left(\mathrm{X}_{7}\right)$ was above the 'Bonferroni Limit', this indicates it is certainly significant. Also the values of $\mathrm{pH}$ $\left(\mathrm{X}_{1}\right)$, yeast extract $\left(\mathrm{X}_{3}\right)$, L-tyrosine $\left(\mathrm{X}_{7}\right)$, and $\mathrm{CuSO}_{4}\left(\mathrm{X}_{8}\right)$ were above the $t$ value limit that implies that these factors are possibly significant. While the remaining factors were below the $t$-value limit which indicates their insignificance [23]. Statistical analysis of the responses was performed, as shown in Table 1. The model $\mathrm{F}$ value of 31.7145 implies that the model is significant. The values of "prob $>$ F" less than 0.05 indicate model terms are significant. "Adeq Precision" measures the signal-to-noise ratio, with a ratio greater than 4 regarded as desirable [23]. The "Adeq Precision" ratio of 9.007 obtained in this study indicates an adequate signal. Thus, this model can be used to navigate the design space. Statistical analysis showed that it is not possible to evaluate the relationship between significant independent variables and the response by a first-order equation. Thus, the first-order model is not appropriate to predict the response; hence the further investigation could be conducted through a second-order model.

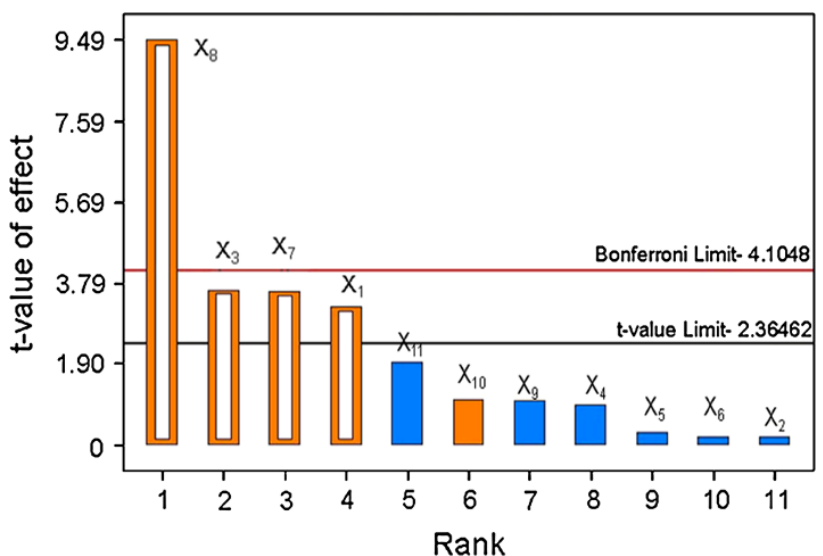

Fig. 1 Pareto chart showing significant effects of factors above the 'Bonferroni Limit' and 't-value Limit' and insignificant effect of the factors below the 'Bonferroni Limit' and 't-value Limit' $X_{1}(\mathrm{pH}), X_{2}$ (temperature), $\mathrm{X}_{3}$ (yeast extract), $\mathrm{X}_{4}$ (peptone), $\mathrm{X}_{5}$ (beef extract), $\mathrm{X}_{6}$ (sucrose), $\mathrm{X}_{7}$ (L-tyrosine), $\mathrm{X}_{8}\left(\mathrm{CuSO}_{4}\right), \mathrm{X}_{9}\left(\mathrm{MgSO}_{4}\right), \mathrm{X}_{10}\left(\mathrm{~K}_{2} \mathrm{HPO}_{4}\right)$, and $\mathrm{X}_{11}$ (Thiamine)

Table 1 Statistical analysis of the model by Plackett-Burman design for L-DOPA production

\begin{tabular}{|c|c|c|c|c|c|}
\hline Source & $\begin{array}{l}\text { Sum of } \\
\text { Squares }\end{array}$ & $\mathrm{df}$ & $\begin{array}{l}\text { Mean } \\
\text { square }\end{array}$ & $\mathrm{F}$ value & $\begin{array}{l}P \text { value } \\
\text { Prob }>\mathrm{F}\end{array}$ \\
\hline Model & 0.101625 & 4 & 0.025406 & 31.7145 & $0.0001 *$ \\
\hline $\mathrm{X}_{1}-\mathrm{pH}$ & 0.008427 & 1 & 0.008427 & 10.51935 & $0.0142 *$ \\
\hline $\mathrm{X}_{3}$-yeast extract & 0.01068 & 1 & 0.01068 & 13.33216 & $0.0082 *$ \\
\hline $\mathrm{X}_{7}$-L-tyrosine & 0.072075 & 1 & 0.072075 & 89.97058 & $<0.0001 *$ \\
\hline $\mathrm{X}_{8}-\mathrm{CuSO}_{4}$ & 0.010443 & 1 & 0.010443 & 13.0359 & 0.0086 \\
\hline Residual & 0.02175 & 7 & 0.02175 & & \\
\hline Cor total & 0.005608 & 12 & & & \\
\hline
\end{tabular}

$P<0.05, *$ Significant $P$ value

\subsection{Box-Behnken Design}

Further optimization of the factors that found to be significant from the Plackett-Burman design were carried out which included $\mathrm{pH}\left(\mathrm{X}_{1}\right)$, yeast extract $\left(\mathrm{X}_{3}\right)$, L-tyrosine $\left(\mathrm{X}_{7}\right)$, and $\mathrm{CuSO}_{4}\left(\mathrm{X}_{8}\right)$. The results obtained were submitted to ANOVA using the Design expert software and results were presented in Table 2 (version 8.0, Stat-Ease Inc. USA), and the regression model equation was given as:

$$
\begin{aligned}
\text { L-DOPA }= & 1.31-0.077 \mathrm{X}_{1}+0.18 \mathrm{X}_{3}+0.19 \mathrm{X}_{7} \\
& +0.15 \mathrm{X}_{8}-0.17 \mathrm{X}_{1} \mathrm{X}_{3}-0.21 \mathrm{X}_{1} \mathrm{X}_{7} \\
& -0.11 \mathrm{X}_{1} \mathrm{X}_{8}+0.071 \mathrm{X}_{3} \mathrm{X}_{7}+0.089 \mathrm{X}_{3} \mathrm{X}_{8} \\
& +0.13 \mathrm{X}_{7} \mathrm{X}_{8}-0.54 \mathrm{X}_{1}^{2}-0.32 \mathrm{X}_{3}^{2} \\
& -0.25 \mathrm{X}_{7}^{2}-0.28 \mathrm{X}_{8}^{2}
\end{aligned}
$$


Table 2 Analysis of variance (ANOVA) for the fitted quadratic polynomial model of L-DOPA production

\begin{tabular}{|c|c|c|c|c|c|}
\hline Source & $\begin{array}{l}\text { Sum of } \\
\text { Squares }\end{array}$ & df & $\begin{array}{l}\text { Mean } \\
\text { Square }\end{array}$ & $\mathrm{F}$ value & $\begin{array}{l}P \text { value } \\
\text { Prob }>\text { F }\end{array}$ \\
\hline Model & 4.067057 & 14 & 0.290504 & 19.55822 & $<0.0001^{*}$ \\
\hline $\mathrm{X}_{1}-\mathrm{pH}$ & 0.070994 & 1 & 0.070994 & 4.779684 & $0.0463^{*}$ \\
\hline $\begin{array}{c}\mathrm{X}_{3} \text {-Yeast } \\
\text { extract }\end{array}$ & 0.392047 & 1 & 0.392047 & 26.39459 & $0.0002^{*}$ \\
\hline $\mathrm{X}_{7}$-L-tyrosin & 0.45202 & 1 & 0.45202 & 30.4323 & $<0.0001^{*}$ \\
\hline $\mathrm{X}_{8}-\mathrm{CuSO}_{4}$ & 0.262552 & 1 & 0.262552 & 17.67635 & $0.0009 *$ \\
\hline$X_{1} X_{3}$ & 0.110889 & 1 & 0.110889 & 7.465614 & $0.0162^{*}$ \\
\hline $\mathrm{X}_{1} \mathrm{X}_{7}$ & 0.178929 & 1 & 0.178929 & 12.04641 & $0.0037 *$ \\
\hline$X_{1} X_{8}$ & 0.05267 & 1 & 0.05267 & 3.54603 & 0.0806 \\
\hline $\mathrm{X}_{3} \mathrm{X}_{7}$ & 0.020306 & 1 & 0.020306 & 1.36712 & 0.2618 \\
\hline $\mathrm{X}_{3} \mathrm{X}_{8}$ & 0.032041 & 1 & 0.032041 & 2.157164 & 0.1640 \\
\hline$X_{7} X_{8}$ & 0.069696 & 1 & 0.069696 & 4.692291 & $0.0480 *$ \\
\hline$X_{1}^{2}$ & 1.897243 & 1 & 1.897243 & 127.7321 & $<0.0001^{*}$ \\
\hline$X_{3}^{2}$ & 0.667645 & 1 & 0.667645 & 44.9493 & $<0.0001^{*}$ \\
\hline$X_{7}^{2}$ & 0.408899 & 1 & 0.408899 & 27.52919 & $0.0001 *$ \\
\hline $\mathrm{X}_{8}^{2}$ & 0.514278 & 1 & 0.514278 & 34.6238 & $<0.0001^{*}$ \\
\hline Residual & 0.207946 & 14 & 0.014853 & & \\
\hline Lack of fit & 0.186523 & 10 & 0.018652 & 3.482636 & 0.1203 \\
\hline Pure error & 0.021423 & 4 & 5.3558 & & \\
\hline Cor total & 4.275003 & 28 & & & \\
\hline
\end{tabular}

$P<0.05$, * Significant $P$ value

where $\mathrm{X}_{1}$ is $\mathrm{pH}, \mathrm{X}_{3}$ is yeast extract, $\mathrm{X}_{7}$ is L-tyrosine, and $\mathrm{X}_{8}$ is $\mathrm{CuSO}_{4}$. The ANOVA of the quadratic regression model (Table 2) demonstrated that Eq. (1) is a highly significant model $(P=0.001)$. The model $\mathrm{F}$ value of 19.55 implies that the model was significant. The goodness of fit of the model was checked using the determination coefficient $\left(R^{2}\right)$. In this case, the value of the $R^{2}$ was 0.9514 . The value of the adjusted determination coefficient (Adj $\left.R^{2}=0.9027\right)$ was in reasonable agreement with the Pred $\mathrm{R}^{2}$ (0.7409). The lack-of-fit value (0.1203) for this model was not significant relative to the pure error, which was good to fit the model. "Adeq Precision" measures the signal-to-noise ratio [23]. The "Adeq Precision" ratio of 30.520 obtained in this study indicates an adequate signal. Thus, this model can be used to navigate the design space.

\subsection{Three-Dimensional (3D) Response Surface Curves}

3D graphs were generated for the pair wise combination of the four factors while keeping the other two at their optimum levels for L-DOPA production. The graphs are given here to highlight the roles played by various factors in the final yield of L-DOPA. The response surface plot (Fig. 2a) of the interaction of $\mathrm{pH}$ and yeast extract indicates that interaction of these components significantly affected the production of L-DOPA. The higher and lower levels of these components affect the L-DOPA yield drastically while mid-levels provide a maximum yield. The interaction between $\mathrm{pH}$ and yeast extract was found to significant because acidic and alkaline $\mathrm{pH}$ results in lower L-DOPA yields might be because of inhibited tyrosinase activity and cell viability. Also at alkaline $\mathrm{pH}$, less L-DOPA yield resulted due to the conversion of L-DOPA into further metabolites like dopaquinone and melanin [9]. Previous reports shows that Egyptian Black Yeast produced L-DOPA at $10 \mathrm{pH}$ [14], while $Y$. lipolytica NRRL-143 and A. oryzae shows the L-DOPA production at acidic condition; 3.5 and 5.4 respectively $[9,10]$.

The response surface curve (Fig. 2b) of the interaction between $\mathrm{pH}$ and L-tyrosine showed that L-DOPA production was drastically affected by the levels of these factors. The higher and lower concentrations of both factors resulted in lesser L-DOPA yield. The interaction between $\mathrm{pH}$ and L-tyrosine was found to highly significant because its solubility is decreases at neutral and alkaline conditions while L-tyrosine soluble at acidic conditions [11, 24]. The higher concentration of L-tyrosine inhibited the L-DOPA production due to its decreased solubility [10, 25].

The interaction between $\mathrm{pH}$ and $\mathrm{CuSO}_{4}$ less significantly affect the yield of L-DOPA. The statistical analysis showed the insignificant $P$ value (0.806) for this interaction (Fig. 2c; Table 2). In addition, the interaction between yeast extract and L-tyrosine (Fig. 2d) found to be insignificant. The effect of the interaction between yeast extract and $\mathrm{CuSO}_{4}$ (Fig. 2e) indicates that the L-DOPA yield was not highly altered by changes in the concentration of both media components. The shape of the response surface curve and statistical analysis (Table 2) indicate that highly insignificant interaction occurred between these factors.

The response surface curve of L-tyrosine and $\mathrm{CuSO}_{4}$ (Fig. 2f) showed a positive effect on L-DOPA production because the tyrosinase involved in the conversion of L-tyrosine to L-DOPA is a copper-containing enzyme [26]. The use of $\mathrm{CuSO}_{4}$ in the media for L-DOPA production by A. rutilum has been reported earlier [13].

\subsection{Validation of the Experimental Model}

Validation was carried out under conditions predicted by the model. The optimized levels predicted by the model were $\mathrm{pH} 6.1,1.659 \mathrm{~g} \mathrm{~L}^{-1}$ yeast extract, $1.491 \mathrm{~g} \mathrm{~L}^{-1}$ L-tyrosine and $0.0290 \mathrm{~g} \mathrm{~L}^{-1} \mathrm{CuSO}_{4}$. The predicted yield of L-DOPA with these concentrations was $1.319 \mathrm{~g} \mathrm{~L}^{-1}$, while the actual yield obtained was $1.273 \mathrm{~g} \mathrm{~L}^{-1}$. A close correlation between the experimental and predicted values was observed, which validates this model. 

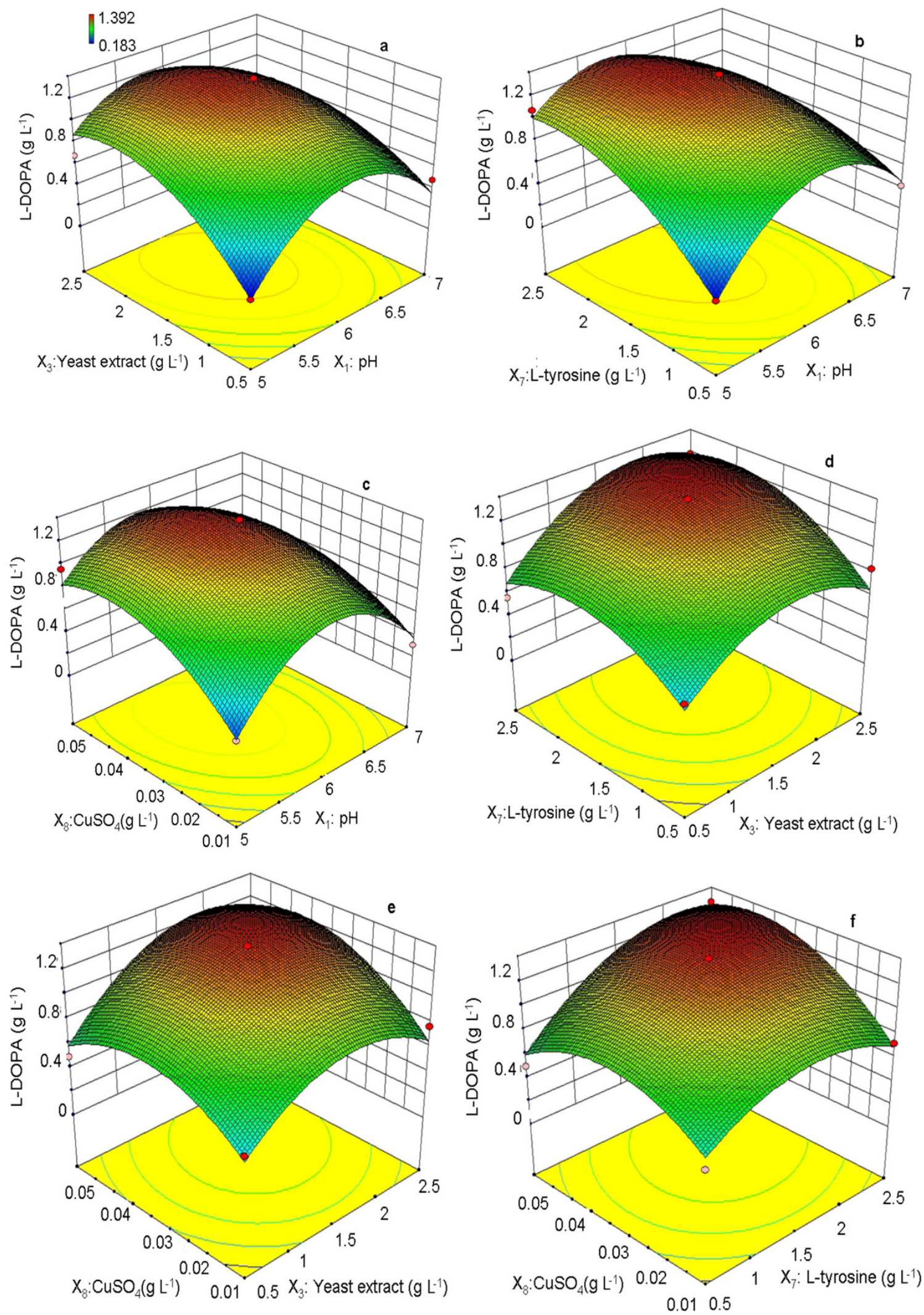

Fig. 2 Three-dimensional response surface curve showing the effect of interactions of a $\mathrm{pH}$ and yeast extract $\mathbf{b} \mathrm{pH}$ and $\mathrm{L}$-tyrosine $\mathbf{c} \mathrm{pH}$ and $\mathrm{CuSO}_{4} \mathbf{d}$ yeast extract and L-tyrosine e yeast extract and $\mathrm{CuSO}_{4} \mathbf{f}$ L-tyrosine and $\mathrm{CuSO}_{4}$ 


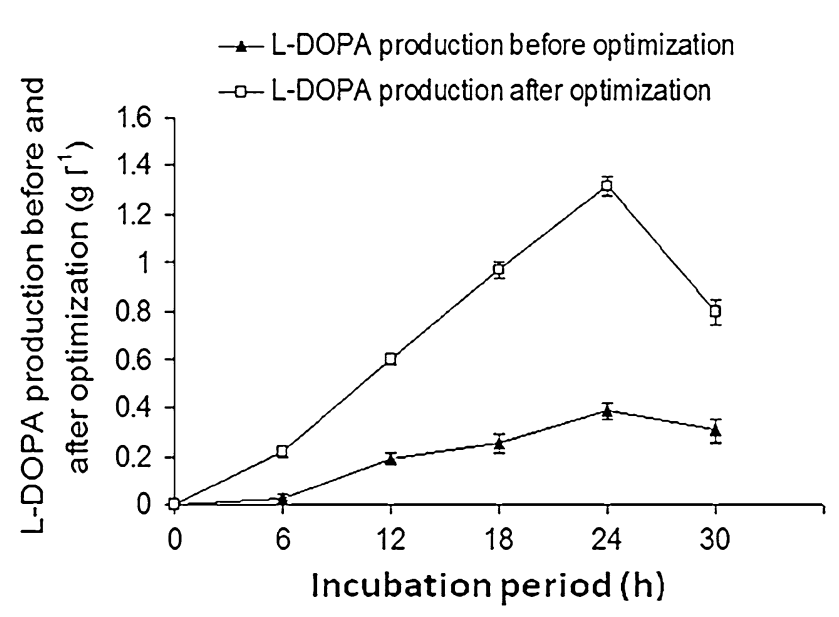

Fig. 3 L-DOPA production before and after optimization by RSM

\subsection{L-DOPA Yield and Tyrosinase Activity}

The L-DOPA production before and after optimization is depicted in Fig. 3, which indicates that in the medium before optimization, L-DOPA production started after the 6th hour with a yield of $0.0261 \mathrm{~g} \mathrm{~L}^{-1}$, gradually increased to $0.387 \mathrm{~g} \mathrm{~L}^{-1}$ at the 24th hour, and then decreased to $0.307 \mathrm{~g} \mathrm{~L}^{-1}$ at the 30th hour. In contrast, in the medium optimized by RSM, L-DOPA production started at the 6th hour with a yield of $0.218 \mathrm{~g} \mathrm{~L}^{-1}$, gradually increased to $1.391 \mathrm{~g} \mathrm{~L}^{-1}$ at the 24th hour, and finally decreased to $0.794 \mathrm{~g} \mathrm{~L}^{-1}$ at the 30 th hour. The decrease in the L-DOPA yield after the 18th hour was due to the conversion of L-DOPA to further metabolites, such as dopaquinone and melanin $[10,11]$. Thus, the medium optimization by RSM resulted in a 3.594-fold increase in the L-DOPA yield over the yield before optimization. The literature survey revealed that single and multiple stage cell suspension cultures of $M$. pruriens have been reported to yield $0.028 \mathrm{~g} \mathrm{~L}^{-1}$ L-DOPA within 15 and 30 days, respectively [17]. P grandiflora has been reported to produce $0.488 \mathrm{~g} \mathrm{~L}^{-1}$ of L-DOPA at the 16th hour [16]; A. rutilum produced $0.89 \mathrm{~g} \mathrm{~L}^{-1} \mathrm{~L}$-DOPA, whereas Egyptian black yeast yielded $0.064 \mathrm{~g} \mathrm{~L}^{-1}[13,14]$. Thus $Y$. lipolyticaNCIM 3450 in the present study produced the highest yield of L-DOPA $\left(1.273 \mathrm{~g} \mathrm{~L}^{-1}\right)$. The Y. lipolytica-NCIM 3450 reported here produced maximum L-DOPA and has several advantages over the plant, fungal, and bacterial sources used earlier, such as a short incubation period, efficient production, and requirement of simple medium components. The L-DOPA produced previously by bacterial sources like E. herbicola used pyrocatechol as substrate, which is a toxic phenolic compound, and required polyacrylamide gel, which is an expensive chemical $[8,11]$. Thus, the present study contributes to the optimization of the nutritional requirements that will be most useful for large-scale production of L-DOPA using Y. lipolyticaNCIM 3450. The highest tyrosinase activity was found to be $2738 \mathrm{U} \mathrm{mg}^{-1}$. On the other hand, some pycnoporus species $P$. sanguineus, Edible mushroom, bacteria Thermomicrobium roseum and yeast $Y$. lipolytica NRRL-143 have Specific activity 30, 21.92, 2.49 and $1.55 \mathrm{U} \mathrm{mg}^{-1}$ respectively [10, 27-29].

\subsection{Analysis of L-DOPA by HPTLC and HPLC}

The HPTLC peak profile and the HPTLC plate (Electronic supplementary material Fig. S1) of the cell-free broth showed a distinct peak and band at the RF 0.24, which was identical to standard L-DOPA (0.23). These results primarily confirmed the L-DOPA production in the medium. The HPLC elution profile of standard L-DOPA showed a peak at the retention time $2.723 \mathrm{~min}$ (Electronic supplementary material Fig. S2), while the HPLC elution profile of the broth after incubation showed a prominent peak at the retention time $2.721 \mathrm{~min}$. This analysis confirmed the production of L-DOPA.

\section{Experimental Section}

\subsection{Chemicals, Strain and L-DOPA Production}

L-tyrosine and L-DOPA were purchased from SigmaAldrich (St Louis, MO, USA) and all other chemicals were obtained from Himedia (India). The strain Y. lipolyticaNCIM 3450 was purchased from National Collection of Industrial Microorganism (NCIM), Pune, India. The medium for the cultivation of the $Y$. lipolytica strain composed of $1 \mathrm{~g} \mathrm{~L}^{-1}$ yeast extract, $0.5 \mathrm{~g} \mathrm{~L}^{-1}$ peptone, $0.5 \mathrm{~g} \mathrm{~L}^{-1}$ glucose and $1 \mathrm{~g} \mathrm{~L}^{-1}$ L-tyrosine at $\mathrm{pH}$ 7. The stock cultures of yeast strain were maintained routinely on this medium and stored at $4{ }^{\circ} \mathrm{C}$ until used. L-DOPA production was carried out in $250 \mathrm{~mL}$ Erlenmeyer flask containing medium mentioned earlier. These flasks were kept in an incubator shaker at $30{ }^{\circ} \mathrm{C}$ and $120 \mathrm{rpm}$ for $24 \mathrm{~h}$. L-DOPA was assayed in cell free broth which was obtained after centrifugation at $5000 \mathrm{rpm}$. The optimization of L-DOPA production was carried out by using Plackett-Burman design and RSM.

\subsection{Screening of the Critical Factors Using a Plackett- Burman Design}

Plackett-Burman design, an efficient technique for medium component optimization, was used to pick factors that significantly influenced L-DOPA production and insignificant ones were eliminated in order to obtain a smaller, more manageable set of factors. The factors affecting the yield of 
L-DOPA were selected by screening various carbon sources, nitrogen sources, mineral salts and physical factors such as $\mathrm{pH}$ and temperature. In addition, some of these variables were selected from the primary literature review $[13,14]$. A total of 11 process parameters, including $\mathrm{X}_{1}(\mathrm{pH}), \mathrm{X}_{2}$ (Temperature), $\mathrm{X}_{3}$ (Yeast extract), $\mathrm{X}_{4}$ (Peptone), $\mathrm{X}_{5}$ (Beef extract), $\mathrm{X}_{6}($ Sucrose $), \mathrm{X}_{7}$ (L-tyrosine), $\mathrm{X}_{8}\left(\mathrm{CuSO}_{4}\right), \mathrm{X}_{9}\left(\mathrm{MgSO}_{4}\right), \mathrm{X}_{10}$ $\left(\mathrm{K}_{2} \mathrm{HPO}_{4}\right), \mathrm{X}_{11}$ (Thiamine) were added at two levels: low $(-1)$ and high $(+1)$. The low and high levels of these factors were taken as $\mathrm{pH}(5$ and 7$)$, temperature $\left(20{ }^{\circ} \mathrm{C}\right.$ and $\left.50{ }^{\circ} \mathrm{C}\right)$. While levels of media components were $\left(\mathrm{g} \mathrm{L}^{-1}\right)$ : yeast extract $(0.5$ and 2.5), peptone (0.5 and 2.5), beef extract (0.5 and 2.5), sucrose (0.5 and 2.5), L-tyrosine (0.5 and 2.5), $\mathrm{CuSO}_{4}(0.01$ and 0.05), $\mathrm{MgSO}_{4}(0.001$ and 0.005$), \mathrm{K}_{2} \mathrm{HPO}_{4}(0.5$ and 2.5) and thiamine $(0.001$ and 0.005$)$. The full experimental plan with L-DOPA yield is presented in Electronic supplementary material Table $S 1$. The statistical significance of the first-order model was identified using Fisher's test for analysis of variance (ANOVA) by Design expert software (version 8.0, StatEase Inc. USA). Moreover, the multiple correlation coefficients $\left(\mathrm{R}^{2}\right)$ were used to express the fit of this first model.

\subsection{Optimization by Box-Behnken Design}

Based on the results of Plackett-Burman experiments, critical factors were further optimized. The variables each at levels with three replicates at the centre points [23, 30] was used to fit a polynomial model. The experimental plan with L-DOPA yield for Box-Behnken design is given in Electronic supplementary material Table S2. A multiple regression analysis of the data was carried out to define the response in terms of the independent variables. Response surface graphs were obtained to understand the effect of the variables, individually and in combination, and to determine their optimum levels for maximum L-DOPA production by using Design expert software (version 8.0, StatEase Inc. USA). All trials were performed in triplicate, and the average L-DOPA yield was used as response $\mathrm{Y}$.

\subsection{L-DOPA Production and Tyrosinase Activity}

After validation of the experiment using the optimum process parameters generated by the Design Expert software, the L-DOPA production was observed in the medium before optimization and after optimization. The L-DOPA production was observed at 6-h of time intervals for up to $24 \mathrm{~h}$. The tyrosinase activity was observed at optimum incubation period.

\subsection{Analysis of L-DOPA by HPTLC and HPLC}

High-performance thin-layer chromatography (HPTLC) analysis of the cell-free broth was performed using a
HPTLC system (CAMAG, Switzerland). The conditions used for HPTLC were similar to those in the previously described method [12]. High-performance liquid chromatography (HPLC) analysis of the cell-free broth was carried out (Waters model no. 2690) on a C18 column (4.6 mm $\times 250 \mathrm{~mm}$, Symmetry) using methanol as mobile phase, with a flow rate of $1 \mathrm{~mL} \mathrm{~min}{ }^{-1}$ for $10 \mathrm{~min}$ and a UV detector at $280 \mathrm{~nm}$. The standard L-DOPA and cellfree broth were prepared in HPLC-grade water and injected into the HPLC column $[11,13]$.

\subsection{L-DOPA and Tyrosinase Assay}

L-DOPA produced in the broth was determined according to Arnow's method [25]. The tyrosinase activity was determined by the previously described method [10, 12, 31]. The protein content in the cell free broth was determined using Lowry's method [32].

\section{Conclusion}

Thus, statistical method not only helped in locating the optimum levels of the most significant factors considered with minimum resources and time but also proved to be useful and satisfactory in this process-optimizing exercise. The optimization of vital nutritional parameters by using RSM significantly enhanced the yield of L-DOPA as proved its feasibility of the process for large scale production by $Y$. lipolytica-NCIM 3450. So the $Y$. lipolyticaNCIM 3450 can be a potential source for L-DOPA production.

Acknowledgments Swati T. Gurme thankful to the Department of Science and Technology, Government of India, for providing those fellowships under the DST-PURSE program. Dr. Shripad N. Surwase thanks the Lady Tata Memorial Trust, Mumbai, Maharashtra, India, for awarding him with a Junior Research Scholarship for his doctoral research. Sushama A. Patil thank to the Department of Science and Technology, Government of India, for providing those fellowships under the DST-SAP program. Authors thankful to Karen Dulski Communications Specialist Stat-Ease Inc. USA for extending the trial period of Design Expert software (version 8.0, Stat-Ease Inc. USA). Corresponding author wishes to thank Interdisciplinary Programme for Life Sciences sponsored by Dept of Biotechnology Government of India under DBT-IPLS program.

Conflict of interest The authors declare that they have no conflict of interest.

Open Access This article is distributed under the terms of the Creative Commons Attribution License which permits any use, distribution, and reproduction in any medium, provided the original author(s) and the source are credited. 


\section{References}

1. J.K. Rarveen, L.C. Michael, Clinical Medicines, ELBS, 2nd edn. (CBS, London, 1992)

2. K. Haneda, S. Watanabe, P. Takeda, J. Ferment. Technol. 51, 398-406 (1973)

3. K. Rosazza, G. Paul, S. Wolf, Biotechnol. Lett. 16, 210-215 (1995)

4. L.T. Kim, B.J. Heo, H.P. Kim, J. Cosmet. Sci. 19, 291-298 (1997)

5. A. Antson, T. Demidkina, P. Gollnick, Z. Dauter, R. von Tersch, J. Long, S. Berezhnoy, R. Phillips, E. Harutyunyan, K. Wilson, Biochemistry 32, 4195-4206 (1993)

6. H. Kumagai, H. Yamada, H. Matsui, H. Ohkishi, K. Ogata, J. Biol. Chem. 245, 1767-1772 (1970)

7. S. Huang, S. Chen, K. Wu, W.J. Taung, Ferment. Bioeng. 79, 342-347 (1995)

8. T. Koyanagi, T. Katayama, H. Suzuki, H. Nakazawab, K. Yokozeki, H. Kumagai, J. Biotechnol. 115, 303-306 (2005)

9. S. Ali, I. Haq, Curr. Microbiol. 53, 351-357 (2006)

10. S. Ali, S. Jeffry, I. Haq, BMC Biotechnol. 7, 50-57 (2007)

11. S.N. Surwase, J.P. Jadhav, Amino Acids 41, 495-506 (2011)

12. S.N. Surwase, S.A. Patil, O.A. Apine, J.P. Jadhav, Appl. Biochem. Biotechnol. 167, 1015-1028 (2012)

13. R. Krishnaveni, V. Rathod, M. Thakur, Y. Neelgund, Curr. Microbiol. 58, 122-128 (2009)

14. D. Mahmoud, M. Bendary, World J. Microbiol Biotechnol. (2010). doi:10.1007/s11274-010-0424-5

15. V. Bapat, P. Suprasanna, T. Ganapathi, P. Rao, Pharm Biol. 38, 271-273 (2000)

16. N. Rani, B. Joy, T. Abraham, Pharm. Biol. 45, 48-53 (2007)
17. S. Chattopadhyay, S. Datta, S. Mahato, Plant Cell Rep. 13, 519-522 (1994)

18. S. Inamdar, S. Joshi, J. Jadhav, V.J. Bapat, Nat. Prod. Bioprospect. 2, 16-20 (2012)

19. H. Blaser, F. Spindler, M. Studer, Appl. Catal. A. 221, 119-143 (2001)

20. M. Tanyildizi, D. Ozer, M. Elibol, Process Biochem. 40, 2291-2296 (2005)

21. M. Aghaie-Khouzania, H. Forootanfara, M. Moshfegha, M.R. Khoshayandc, M.A. Faramarzia, Biochem Eng. 60, 9-15 (2012)

22. S. Jadhav, S. Surwase, S. Phugare, J. Jadhav, Int. J. Environ. Sci. Technol. 10, 181-190 (2012)

23. M. Anderson, P. Whitcomb, RSM Simplified (Productivity press, New York, 2005)

24. V. Lagunas-Muñoz, N. Cabrera-Valladares, F. Bolívar, G. Gosset, A. Martínez, J. Appl. Microbiol. 101, 1002-1008 (2006)

25. E. Arnow, J. Biochem. 118, 531-537 (1937)

26. H. Claus, H. Decker, Appl. Microbiol. 29, 3-14 (2006)

27. S. Halaouli, Mi Asther, K. Kruus, L. Guo, M. Hamdi, J.-C. Sigoillot, M. Asther, A. Lomascolo, J. Appl. Microbiol. 98, 332-343 (2005)

28. H. Kamahldin, R. Ferdous, A. Ali, S. Shahrzad, Iran. J. Biotechnol. 2, 189-194 (2004)

29. H. Kwang, P. Min, S. Sang, T. Yong, H. Sung, Biotechnol. Appl. Biochem. 31, 113-118 (2000)

30. G. Box, D. Behnken, Technometrics 2, 455-475 (1960)

31. C. Kandaswami, C.J. Vaidyanathan, Biological Chem. 249, 4035-4039 (1973)

32. O. Lowry, N. Rosbrough, A. Farr, R. Randall, J. Biol. Chem. 193, 265-275 (1951) 